\title{
Correction \\ Correction: Ferraz-Amaro et al. SCORE2 Assessment in The Calculation of Cardiovascular Risk in Patients with Rheumatoid Arthritis. Diagnostics 2021, 11, 2363
}

\author{
Iván Ferraz-Amaro 1,2,*iD, Alfonso Corrales ${ }^{3,4}$, Belén Atienza-Mateo ${ }^{3,4} \mathbb{D}$, Nuria Vegas-Revenga ${ }^{3}$, \\ Diana Prieto-Peña ${ }^{3,4}$, Julio Sánchez-Martín ${ }^{3,4}$, Cristina Almeida ${ }^{5}$, Juan Carlos Quevedo-Abeledo ${ }^{5}$, \\ Ricardo Blanco $^{3,4}$ (D) and Miguel Á. González-Gay ${ }^{3,4,6, *(\mathbb{D}}$
}

check for updates

Citation: Ferraz-Amaro, I.; Corrales, A.; Atienza-Mateo, B.;

Vegas-Revenga, N.; Prieto-Peña, D.; Sánchez-Martín, J.; Almeida, C.; Quevedo-Abeledo, J.C.; Blanco, R.; González-Gay, M.Á. Correction: Ferraz-Amaro et al. SCORE2 Assessment in The Calculation of Cardiovascular Risk in Patients with Rheumatoid Arthritis. Diagnostics 2021, 11, 2363. Diagnostics 2022, 12 , 521. https://doi.org/10.3390/ diagnostics12020521

Received: 29 December 2021

Accepted: 7 January 2022

Published: 18 February 2022

Publisher's Note: MDPI stays neutral with regard to jurisdictional claims in published maps and institutional affiliations.

Copyright: (c) 2022 by the authors. Licensee MDPI, Basel, Switzerland. This article is an open access article distributed under the terms and conditions of the Creative Commons Attribution (CC BY) license (https:// creativecommons.org/licenses/by/ $4.0 /)$.
1 Division of Rheumatology, Hospital Universitario de Canarias, 38320 Tenerife, Spain

2 Internal Medicine Department, University of La Laguna, 38071 Tenerife, Spain

3 Division of Rheumatology, Hospital Universitario Marqués de Valdecilla, Universidad de Cantabria, 39008 Santander, Spain; afcorralesm@hotmail.com (A.C.); mateoatienzabelen@gmail.com (B.A.-M.); nuriavegas2@gmail.com (N.V.-R.); diana.prieto.pena@gmail.com (D.P.-P.); jsm132@hotmail.com (J.S.-M.); rblancovela@gmail.com (R.B.)

4 Epidemiology, Genetics and Atherosclerosis Research Group on Systemic Inflammatory Diseases, Hospital Universitario Marqués de Valdecilla, IDIVAL, 39011 Santander, Spain

5 Division of Rheumatology, Hospital Doctor Negrín, 35010 Las Palmas de Gran Canaria, Spain; almeidasantiago.cristina@gmail.com (C.A.); quevedojcarlos@yahoo.es (J.C.Q.-A.)

6 Cardiovascular Pathophysiology and Genomics Research Unit, School of Physiology, Faculty of Health Sciences, University of the Witwatersrand, Johannesburg 2000, South Africa

* Correspondence: iferrazamaro@hotmail.com (I.F.-A.); miguelaggay@hotmail.com (M.Á.G.-G.)

In the original article [1], there was a mistake in Figure 1 as published. Due to an error in the proofreading stage, ROC curves in that figure do not represent the exact curves. The corrected Figure 1 appears below. The authors apologize for any inconvenience caused and state that the scientific conclusions are unaffected. The original publication has also been updated.
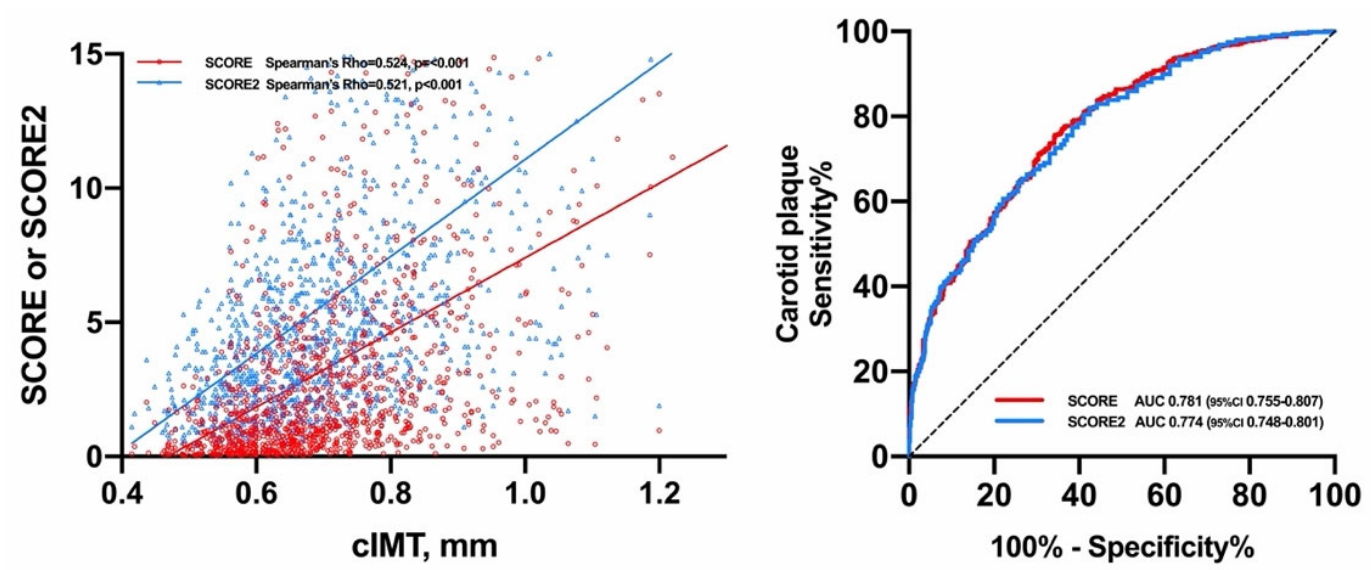

Figure 1. Relationship of SCORE and SCORE2 with cIMT and carotid plaque.

\section{Reference}

1. Ferraz-Amaro, I.; Corrales, A.; Atienza-Mateo, B.; Vegas-Revenga, N.; Prieto-Peña, D.; SánchezMartín, J.; Almeida, C.; Quevedo-Abeledo, J.C.; Blanco, R.; González-Gay, M.Á. SCORE2 Assessment in the Calculation of Cardiovascular Risk in Patients with Rheumatoid Arthritis. Diagnostics 2021, 11, 2363. [CrossRef] [PubMed] 